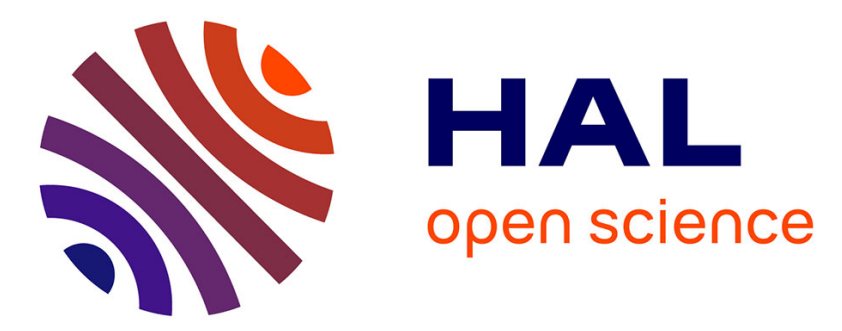

\title{
Plant Cell wall inspired Xyloglucan/Cellulose Nanocrystals Aerogels Produced By Freeze-Casting
}

Z. Jaafar, B. Quelennec, C. Moreau, D. Lourdin, J.E. E Maigret, B. Pontoire, A. D'orlando, T. Coradin, Benoît Duchemin, F.M. Fernandes, et al.

\section{- To cite this version:}

Z. Jaafar, B. Quelennec, C. Moreau, D. Lourdin, J.E. E Maigret, et al.. Plant Cell wall inspired Xyloglucan/Cellulose Nanocrystals Aerogels Produced By Freeze-Casting. Carbohydrate Polymers, 2020, 247, pp.116642. 10.1016/j.carbpol.2020.116642 . hal-02887173

\section{HAL Id: hal-02887173 \\ https://hal.sorbonne-universite.fr/hal-02887173}

Submitted on 2 Jul 2020

HAL is a multi-disciplinary open access archive for the deposit and dissemination of scientific research documents, whether they are published or not. The documents may come from teaching and research institutions in France or abroad, or from public or private research centers.
L'archive ouverte pluridisciplinaire HAL, est destinée au dépôt et à la diffusion de documents scientifiques de niveau recherche, publiés ou non, émanant des établissements d'enseignement et de recherche français ou étrangers, des laboratoires publics ou privés. 
2 Nanocrystals Aerogels Produced By Freeze-Casting

4 PONTOIRE , A. D'ORLANDO ${ }^{1-4}$, T. CORADIN ${ }^{2}$, B. DUCHEMIN ${ }^{3}$, F.M. FERNANDES ${ }^{2}$, B. 


\section{HIGHLIGHTS}

- Non-directional and directional freezing of $\mathrm{CNC} / \mathrm{xyloglycan}$ aerogels is reported

- Addition of xyloglycan (XG) changes aerogel morphology from lamellar to alveolar

- Directional freeze-casting leads to oriented pores ehancing mechanical properties

- Increasing CNC/XG ratio improves mechanical properties of aerogels

- Without chemical cross-linking, such CNC/XG aerogels do not dispersed in water (3)
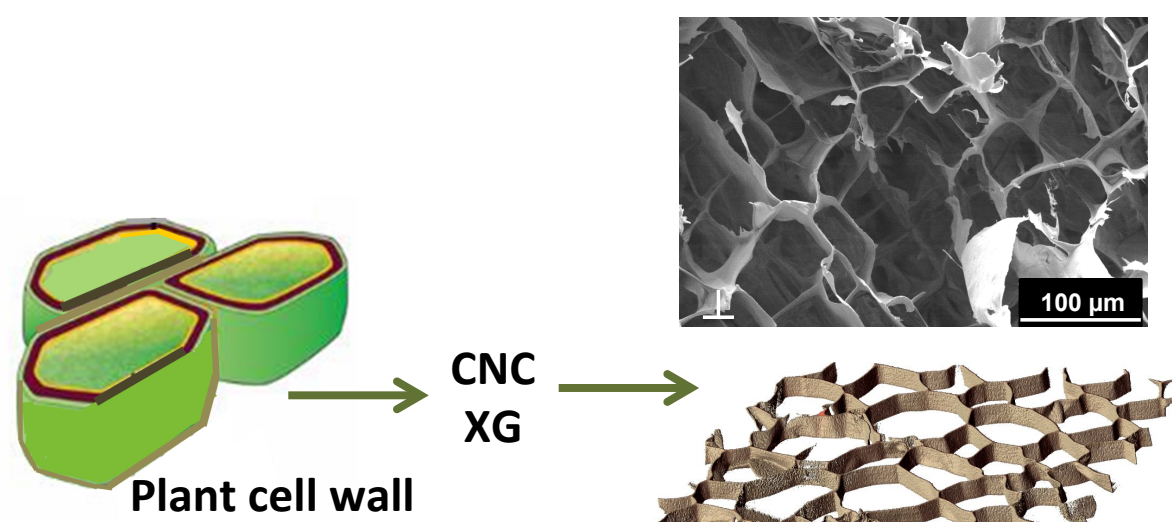

CNC
XG
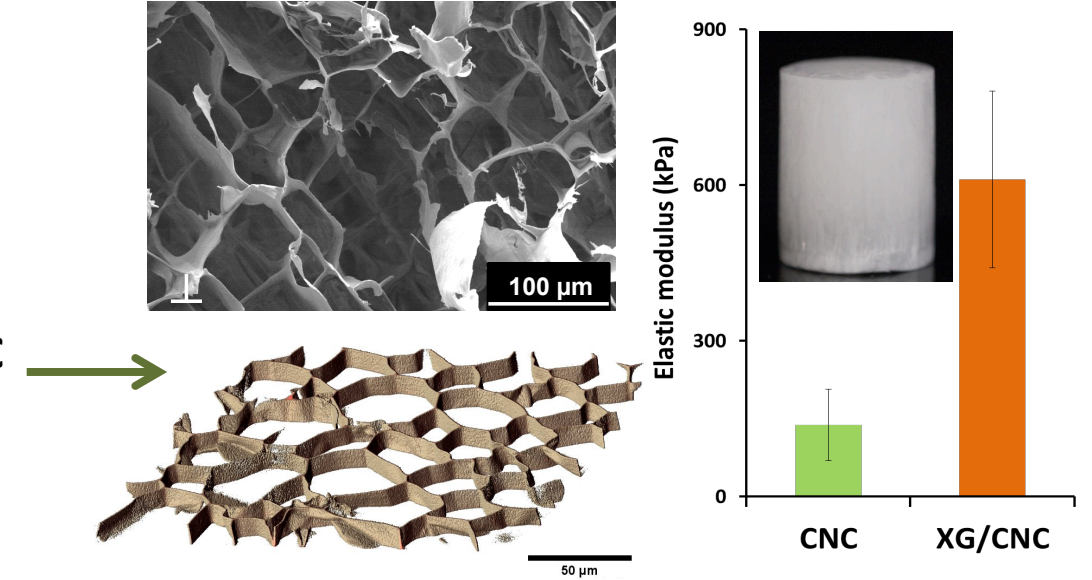

Unidirectional Freeze-casting

Biomimetic plant cell wall aerogels 


\section{ABSTRACT}

38 Cellulose nanocrystals (CNC) and xyloglucan $(\mathrm{XG})$ were used to construct new aerogels inspired

39 by the hierarchical organization of wood tissue, i.e., anisotropic porous cellular solid with pore

40 walls containing oriented and stiff cellulose nanorods embedded in hemicellulose matrix. Aerogels

41 with oriented or disordered pores were prepared by directional and non-directional freeze-casting

42 from colloidal dispersions of $\mathrm{XG}$ and $\mathrm{CNC}$ at different ratios. $\mathrm{XG}$ addition induced a clear

43 improvement of the mechanical properties compared to the $\mathrm{CNC}$ aerogel, as indicated by the

44 Young modulus increase from $138 \mathrm{kPa}$ to $610 \mathrm{kPa}$. The addition of $\mathrm{XG}$ changed the pore 45 morphology from lamellar to alveolar and it also decreased the CNC orientation (the Hermans'

46 orientation factor was 0.52 for $\mathrm{CNC}$ vs $0.36-0.40$ for $\mathrm{CNC}-\mathrm{XG})$. The aerogels that contained the

47 highest proportion of XG also retained their structural integrity in water without any chemical

48 modification. These results open the route to biobased water-resistant materials by an easy and

49 green strategy based on polymer adsorption rather than chemical crosslinking.

50 KEYWORDS: xyloglucan (XG), cellulose nanocrystal (CNC), directional freeze-casting, aerogel,

51 mechanical property

52 
61 Plant stem tissues are highly organized, hierarchical structures. At the tissue level, cells form an

62 anisotropic and porous cellular structure that is oriented along the stem (Cosgrove, 2005; Svagan, 63 Jensen, Dvinskikh, Furó, \& Berglund, 2010). Cell walls are themselves nanostructured since they 64 consist of oriented cellulose nanofibers along the long axis of the fibers and organized in a 65 helicoidal manner. This structural hierarchy is largely responsible for the remarkable mechanical 66 properties of plant cell walls that also display low density and resistance to pathogens and other 67 stresses (Burgert, 2006; Lakes, 1993). The main cell wall components, namely cellulose, 68 hemicellulose and lignin, form a complex network in which they act cooperatively and thereby 69 determine the mechanical behavior of the entire cell wall (Burgert, 2006; Cosgrove, 2005). The 70 whole structural role of hemicelluloses in the cell wall is not fully established, but hemicelluloses 71 are considered to contribute to load transfer and connecting cellulose fibers (Lopez-Sanchez et al., 72 2015).

73 Cellulose nanocrystals (CNC) are rod-like nanoparticles prepared by the removal of disordered 74 parts of cellulose fibers (Klemm et al., 2011). Because of their impressive mechanical properties 75 and nanometric dimensions, they have recently been used as reinforcement materials in composite 76 films, hydrogels and aerogels (Karaaslan, Tshabalala, Yelle, \& Buschle-Diller, 2011; Saxena, 77 Elder, Pan, \& Ragauskas, 2009). Xyloglucans (XG) are hemicelluloses displaying a large 78 structural variability present in the primary plant cell wall. XG is believed to contribute to the 
mechanical properties of the plant cell walls (Cosgrove, 2014; Scheller \& Ulvskov, 2010), since XG has a high affinity to cellulose and adsorbs irreversibly on cellulosic surfaces (Cosgrove,

81 2014). It has been shown that $\mathrm{XG}$ adopts different conformations when adsorbed on CNC, depending on the $\mathrm{CNC} / \mathrm{XG}$ concentration ratios: at low ratios, almost all $\mathrm{XG}$ chains bind as trains to the CNC surface, whereas at high ratios, XG forms more loops and tails (Dammak et al., 2015;

84 Villares, Moreau, Dammak, Capron, \& Cathala, 2015). Here, we hypothesize that such conformational variations might affect the properties of cellulose/XG assemblies.

86 Aerogels are materials derived from hydrogels in which the liquid phase has been replaced by a 87 gas in mild conditions. They are characterized by a very high porous volume $(>90 \%)$ and display 88 interesting properties (Fricke \& Tillotson, 1997). Among the different techniques used to create 89 porous materials, freeze-casting is a versatile and easy to implement technique. Freeze-casting 90 involves unidirectional freezing of a colloidal suspension or a solution following a predefined 91 thermal gradient (Deville, 2010). In water, due to the limited solubility of most compounds in ice, 92 most solutes and/or suspended particles are segregated from the growing ice front into the 93 interstitial space defined by ice crystals. Subsequent solvent sublimation leads to the formation of 94 aerogels whose porosity reproduces the ice crystals' morphology (Deville, 2008). Bioaerogels, i.e. 95 aerogels prepared from natural materials, with homogeneous and well-defined architectures have 96 been a subject of primary interest because of their potential applications in areas such as thermal 97 insulation (Wicklein et al., 2015), tissue engineering (Ghorbani, Nojehdehian, \& Zamanian, 2016; 98 Yin, Divakar, \& Wegst, 2019), drug delivery (Szepes, Ulrich, Farkas, Kovács, \& Szabó-Révész, 99 2007) and automotive components (Köhnke, Lin, Elder, Theliander, \& Ragauskas, 2012; Lee \& 100 Deng, 2011). It was found that the distribution of pore size, pore shape and pore connectivity is 101 the result of the shape of ice crystals formed during freezing (Jiménez-Saelices, Seantier, Grohens, 
102 \& Capron, 2018). Hence, different microstructures and associated functional properties can be 103 obtained by controlling operating parameters such as the freezing rate (or ice front velocity), the 104 interfacial free energy between the particles and the liquid, the interaction of the particles with 105 themselves, as well as the size, distribution and concentration of the particles (Deville, Saiz, \& 106 Tomsia, 2006).

107 A number of $\mathrm{CNC}$ aerogels prepared by freeze-casting have been reported in the literature (Chau 108 et al., 2016; Chu, Qu, Zussman, \& Xu, 2017; Dash, Li, \& Ragauskas, 2012; Munier, Gordeyeva, 109 Bergström, \& Fall, 2016). However, only few studies have focused on CNC-hemicelluloses 110 hydrogels (Karaaslan et al., 2011; Köhnke, Elder, Theliander, \& Ragauskas, 2014; Lopez-Sanchez 111 et al., 2015) or aerogels (De France, Hoare, \& Cranston, 2017; Köhnke et al., 2014; Köhnke et al., 112 2012). These examples, however, rely on chemical modification of CNC or hemicelluloses in order 113 to promote polymer-polymer interactions. In contrast, the present study is devoted to the use of $114 \mathrm{XG}$ and $\mathrm{CNC}$ without any chemical pretreatment, taking advantage of their physical interactions 115 and of the different conformations of XG adsorbed on CNC (Dammak et al., 2015). These 116 conformations were controlled by varying the $\mathrm{CNC} / \mathrm{XG}$ concentration ratios (Dammak et al., 117 2015) in order to develop bioaerogels with cellular structures that mimic the structural and 118 mechanical properties of the plant cell wall (Kam et al., 2019; Pan et al., 2016). In order to elucidate 119 the interplay between $\mathrm{CNC} / \mathrm{XG}$ interactions and the properties of freeze-cast materials, they were 120 compared to reference aerogels of the same composition obtained by non-directional freezing. 121 With the aim of providing an integrated vision of these $\mathrm{CNC} / \mathrm{XG}$ aerogels, we combined a 122 multiscale (from nano- to macro-scale) structural approach using X-ray diffraction (XRD) to 123 assess the orientation of the CNCs, scanning electron microscopy and confocal microscopy to 124 investigate the porous structure, mechanical testing and water immersion conditions to study their 
125 physical and chemical stability. On this basis, it was possible to unveil the multifaceted influence 126 of $\mathrm{XG}$ on the macroscopic properties of biobased and biological materials.

\section{MATERIALS AND METHODS}

$129 \quad 2.1$ Chemicals

130 CNCs obtained from acid hydrolysis of bleached softwood kraft pulp were provided by 131 CelluForce (Montreal, Canada). Product specifications are the following : crystalline fraction $=$ 1320.88 (by XRD), surface charge density $=0.023 \mathrm{mmol} / \mathrm{g}$ (by conductivity), lateral dimension $=2.3-$ $1334.5 \mathrm{~nm}$ (by AFM), length $=44-108 \mathrm{~nm}$ (by AFM). Aqueous CNC suspension (60 g.L-1) was

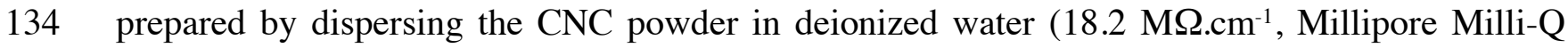
135 purification system) under vigorous stirring with a magnetic stirring bar overnight until it appeared 136 to be well-dispersed according to visual inspection. Afterwards, the dispersion was sonicated for $13710 \mathrm{~min}$ in an ice bath to avoid overheating, using a QSonica Q700 sonicator (20 kHz, QSonica 138 LLC, Newtown, USA) with a $12.7 \mathrm{~mm}$ in diameter ultrasound probe (50 W with $50 \%$ amplitude). 139 Xyloglucan from Tamarindus indica was provided by Megazyme (Bray, County Wicklow, 140 Ireland). Monosaccharide composition (dry weight \%): Glucose $49.1 \pm 1.1$; Xylose $32.1 \pm 2.3$;

141 Galactose $16.4 \pm 0.6$; Arabinose $2.4 \pm 0.1$. The mass average molar mass was $\overline{M_{w}}=840 \times 10^{3}$ $142 \mathrm{~g} \cdot \mathrm{mol}^{-1}$ and the number average molar mass was $\overline{M_{n}}=677 \times 10^{3} \mathrm{~g} \cdot \mathrm{mol}^{-1}$ (dispersity $Đ=1.24$ ). A 143 XG solution with a $10 \mathrm{~g} . \mathrm{L}^{-1}$ concentration was first prepared. It was then concentrated to $20 \mathrm{~g} . \mathrm{L}^{-1}$ 144 by osmosis in a dialysis membrane (Espectra/Por ${ }^{\circledR}$, cutoff $6-8 \mathrm{kDa}$ ) immersed in a $10 \mathrm{wt} . \%$ 145 aqueous dextran solutions $\left(10^{5} \mathrm{~g} \cdot \mathrm{mol}^{-1}\right)$.

$147 \quad 2.2$ Aerogel preparation 
148 The final concentration of the $\mathrm{CNC} / \mathrm{XG}$ suspensions was fixed at 2 wt.\% dry matter and this 149 concentration was kept constant independently of the CNC:XG ratio. CNC-XG complexes were 150 prepared by mixing dispersed $\mathrm{CNC}$ and $\mathrm{XG}$ at two different concentration ratios: 1.9/0.1 wt.\% and 151 1.6/0.4 wt.\% CNC/XG. The mixtures were respectively denoted CNC1.9 XG0.1 and CNC1.6 $152 \mathrm{XG0.4}$ (Figure 1) and they were left under stirring for $18 \mathrm{~h}$. CNC and CNC/XG aerogels were 153 prepared using unidirectional (UF) and non-directional (NF) freeze-casting methods. The UF 154 device was built in our laboratory according to the literature ${ }^{34,35}$ and consisted of a liquid nitrogen 155 Dewar, a copper bar, a heating element and a polypropylene tube partially inserted in the hot end 156 of the copper bar to hold the sample prior to freezing. It was assembled in such a way that half of 157 the copper bar was plunged into liquid $\mathrm{N}_{2}$ to create a heat sink. In a typical experiment, $3 \mathrm{~mL}$ of 158 the 2 wt.\% CNC-XG mixture was poured in the polypropylene tube, in direct contact with the 159 copper surface. After a 5-min equilibration time at $20^{\circ} \mathrm{C}$, the sample was cooled down to $-60{ }^{\circ} \mathrm{C}$ 160 at a cooling rate of $-1{ }^{\circ} \mathrm{C} \cdot \mathrm{min}^{-1}$, and then removed from the device and placed at $-20{ }^{\circ} \mathrm{C}$ before 161 freeze-drying for $24 \mathrm{~h}$. NF experiments were examined by placing dispersions in a freezer $\left(-20^{\circ} \mathrm{C}\right)$ 162 for approximately $3 \mathrm{~h}$. All the samples were cylinders with a mean diameter (D) of $\approx 10 \mathrm{~mm}$ and 163 a mean initial height $(\mathrm{h})$ of $\approx 20 \mathrm{~mm}$.

164 Ice sublimation was conducted in a Christ Alpha 2-4 LD freeze dryer. The temperature of the 165 freeze dryer condenser was kept below $-60^{\circ} \mathrm{C}$ and the internal pressure stabilized within few 166 minutes to approximately $5.10^{-5}$ bar. The freeze-drying process was left to proceed for $24 \mathrm{~h}$, 167 allowing for the recovery of a dried lightweight solid.

168 The bulk density $\rho_{\text {aerogel }}$ of the aerogels was calculated by dividing their weight by their 169 volume. The weight of aerogels was determined with an analytical balance (Mettler Toledo XS), 170 and their volume was measured with a digital caliper. The void fraction (\%) of the aerogel was 
171 calculated using the equation below where the density of cellulose is: $1500 \mathrm{~kg} \cdot \mathrm{m}^{-3}$.

$$
\Phi=\left(1-\frac{\rho_{\text {aerogel }}}{\rho_{C N C}}\right) * 100
$$

173 To visualize the structure of the aerogels, the foams were manually cut with new scalpel blades.

174 Scanning electron microscopy (SEM) observations were performed on a Thermo Fisher Quattro

175 S. The samples were sputter-coated with $5 \mathrm{~nm}$ of platinum and observed under 3-4 $\mathrm{kV}$ acceleration 176 and $30 \mu \mathrm{A}$ probe current.

179 Labeling was achieved according to the protocol reported by Berder et al.(de Belder \& Granath, 180 1973). Briefly, XG or CNC (1 g) were dissolved/dispersed under stirring in $40 \mathrm{~mL}$ of 181 dimethysulfoxide containing a few drops of pyridine at $65^{\circ} \mathrm{C}$, then $10 \mathrm{mg}$ of fluorescein 182 isothiocyanate (FITC) or rhodamine B isothiocyanate (RBITC) were added with $50 \mu \mathrm{L}$ of 183 dibutyltin dilaurate. The mixture was heated during 2 hours at $95^{\circ} \mathrm{C}$. The solution/suspension was 184 poured in ethanol and the precipitate was resuspended several time in acetone and precipitated 185 again to remove the unbound dye. The precipitate was then dissolved in water and dialyzed against 186 ultra pure water until no UV signal of free dye was detected in the washing solutions. CNC and 187 XG suspensions/solutions were then concentrated by osmosis as described above. The aerogels 188 were also prepared according to the same protocols as described above.

189 Confocal microscopy was performed on a Leica SP5 upright microscope using a Leica HPX CL 190 Apochromat 63x 1.4 oil objective. Samples were sliced perpendicular to the ice growth direction 191 (thickness inferior to $1 \mathrm{~mm}$ ) followed by immersion in oil before imaging. The immersion of 192 samples in oil enabled refractive index matching between the objective, the glass coverslips and 193 the sample porous volume thus minimizing optical refraction and maximizing resolution. No 
194 dissolution or deformation of the foams could be noticed when performing the oil immersion.

195 Sequential images were acquired in $300 \mathrm{~nm}$ z steps. Image analysis was conducted in FIJI software 196 using the Volume Viewer and Coloc2 plugins (Schindelin et al., 2012).

\subsection{Mechanical testing}

199 Longitudinal compression measurements were performed on the dry aerogels. Before testing, all 200 the aerogels were stored for at least one day in the measurement room in order to guarantee the 201 same conditions of temperature $\left(20^{\circ} \mathrm{C}\right)$ and humidity $(\mathrm{RH}=35 \%)$. The mechanical properties were 202 characterized by uniaxial compression experiments in an MTS SYNERGIE 100 machine equipped 203 with a $100 \mathrm{~N}$ load cell. The compression tests were performed up to the maximum load and the 204 compression force was parallel to the temperature gradient used for the manufacturing of the UF 205 samples. The cylindrical samples were compressed between two steel plates. A deformation rate 206 of $3 \mathrm{~mm} \cdot \mathrm{min}^{-1}$ was applied on the top surface of each specimen until the deformation of the sample 207 exceeded 70\%. The corresponding stress-strain curves were obtained for five replicas per sample.

$208 \quad 2.5$ Determination of CNC orientation by X-ray diffraction

209 The diffractograms were recorded on a Bruker-AXS D8 Discover diffractometer. The X-ray beam 210 was produced in a sealed copper tube at $40 \mathrm{kV}$ and $40 \mathrm{~mA}$. The $500-\mu \mathrm{m}$ beam with a $\mathrm{CuK} \alpha 1$ 211 wavelength (1.5405 ̊̊) was collimated and parallelized using two crossed-coupled Göbel mirrors. 212 The X-ray diffraction data were collected using a Vantec 500 two-dimensional detector in the 3$21340^{\circ} 2 . \theta$ range. The samples were placed perpendicular or parallel to the X-ray beam.

214 The azimuthal intensity profiles were used in the calculation of the Herman's orientation factor 215 defined by (Hermans, Hermans, Vermaas, \& Weidinger, 1946):

$$
f=\left[3\left(\cos ^{2} \chi\right)-1\right] / 2
$$


217 Where $f$ is the crystal chain axis orientation factor and $\chi$ is the angle between the chain axis and

218 the reference direction. The value of $\cos ^{2} \chi$ is computed from the azimuthal angular distribution 219 of XRD intensity profile by:

$$
\cos ^{2}(\chi)=\frac{\sum_{0}^{\pi / 2} I(\chi) \sin (\chi) \cos ^{2}(\chi)}{\Sigma_{0}^{\pi / 2} I(\chi) \sin (\chi)}
$$

223 Where $I(\chi)$ Is the angular intensity profil from the XRD pattern. The degree of orientation $f$ is the

224 first term in the expansion of an orientation distribution function which depends on the angle 225 between the chain axis and the reference direction. $f$ is equal to 0 for random orientation and to 1 226 for a perfect alignement (Kim, Oh, \& Islam, 2012).

229 The aerogels were immersed in deionized water containing one drop of blue ink for enhancing 230 the visualization of the wet aerogel. The immersed aerogels were kept at $4^{\circ} \mathrm{C}$ and dispersion was 231 visually evaluated every 12 hours. Photographs were taken at different characteristic times.

\section{RESULTS}

$234 \quad 3.1$ Aerogel preparation

235 Figure 1 gives a schematic description of the different compositions and freezing routes of the 236 aerogels. All the aerogels were prepared by ice templating from suspensions of 2 wt $\%$ total 237 polymer content. Two different $\mathrm{CNC} / \mathrm{XG}$ concentration ratios, 1.9/0.1 wt $\%$ and 1.6/0.4 wt $\%$, were 238 selected corresponding to different adsorption regimes, below and above the required ratio to 239 saturate the CNC surface with XG molecules, respectively (Dammak et al., 2015). Previously 
240 reported saturation range is between $20-30 \mathrm{mg} \mathrm{XG} / \mathrm{g}$ of CNC. Thus, for CNC1.9 XG0.1, the

241 amount of XG is lower than that needed for CNC surface saturation. XG will strech to cover all

242 the $\mathrm{CNC}$ surface available and adsorb in the train conformation. For the CNC1.6 XG0.4 mixture,

$243 \mathrm{XG}$ is close to the saturation concentration. The CNC surface is fully covered, increasing the

244 polymer crowding that will thus adsorb with more loops and tails. (Dammak et al., 2015) CNC2

245 XG0 aerogels were used as references. Aerogels were prepared by both NF where the ice crystals

246 nucleate and grow randomly in diverse directions and UF where the suspension is exposed to a

247 controlled cooling element inducing the growth of ice crystals along the generated thermal gradient

248 (Figure 1) (Deville, 2008). Monolithic and homogeneous aerogels were successfully obtained from

$249 \mathrm{CNC} / \mathrm{XG}$ mixtures with the two freezing methods.

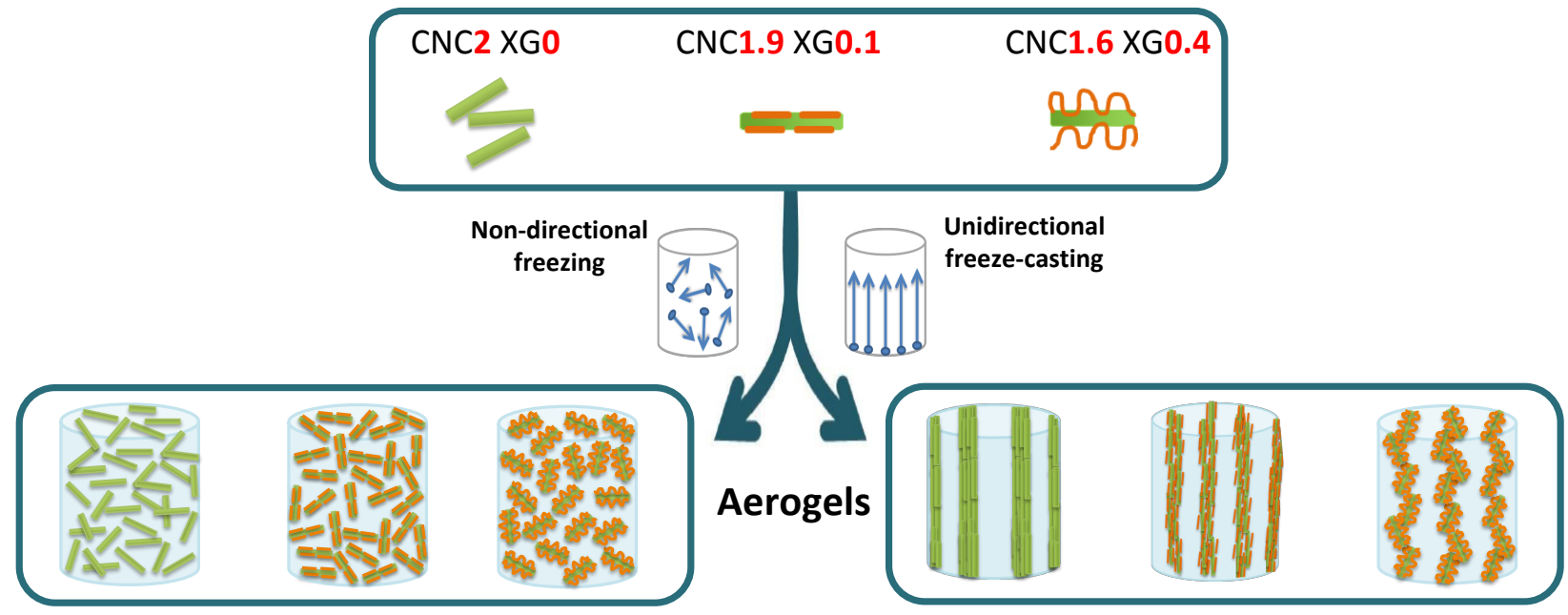

252 Figure 1: Schematic description of the different aerogels with distinct compositions CNC2 XG0;

253 CNC1.9 XG0.1 and CNC1.6 XG0.4, obtained from both non-directional (left) and unidirectional 254 (right) freezing techniques. In the case of $\mathrm{CNC} 1.9 \mathrm{XG}$.1, $\mathrm{XG}$ is adsorbed as trains on the surface 255 of CNCs, while CNC1.6 XG0.4 has the XG adsorbed in the form of loops and tails. Blue arrows 
256 show directions of ice crystals growth. XG and CNC dimensions were not scaled for clarity reasons

257 (the gyration radius of $\mathrm{XG}$ in solution is larger than the $\mathrm{CNC}$ lateral dimensions).

258 Table 1 summarizes the composition and the characteristics of the aerogels. The aerogels

259 based on $2 \% \mathrm{CNC}$ or $2 \% \mathrm{CNC}-\mathrm{XG}$ mixtures have densities of $c a .19 \mathrm{~kg} \cdot \mathrm{m}^{-3}$ when prepared by UF,

260 and ca. $23 \mathrm{~kg} \cdot \mathrm{m}^{-3}$ when prepared by NF. This difference can be correlated with the observed slight

261 decrease in the volume of the aerogels prepared by NF, indicating a small shrinkage of the structure

262 during the drying step of the hydrogel.

263

264 Table1: Characteristics of the different aerogels (CNC2 XG0, CNC1.9 XG0.1 and CNC1 .6 XG0.4)

265 prepared with a final concentration of $2 \mathrm{wt} \%$, by unidirectional freezing (UF) or non-directional 266 freezing $(\mathrm{NF})$.

\begin{tabular}{|c|c|c|c|c|c|c|c|c|}
\hline \multirow[b]{2}{*}{ Aerogel } & \multicolumn{2}{|c|}{ Composition } & \multirow[b]{2}{*}{ Method } & \multirow{2}{*}{$\begin{array}{l}\text { Density } \\
\left(\mathbf{k g}^{\left.-m^{-3}\right)}\right.\end{array}$} & \multirow{2}{*}{$\begin{array}{c}\text { Void } \\
\text { fraction } \\
(\%)\end{array}$} & \multirow{2}{*}{$\begin{array}{c}\text { Elastic } \\
\text { modulus } \\
(\mathbf{k P a})\end{array}$} & \multirow{2}{*}{$\begin{array}{l}\text { Yield } \\
\text { stress } \\
(\mathbf{k P a})\end{array}$} & \multirow{2}{*}{$\begin{array}{c}\text { Herman's } \\
\text { orientation } \\
\text { factor } f\end{array}$} \\
\hline & CNC & $\mathbf{X G}$ & & & & & & \\
\hline CNC2 XG0 & $2 \%$ & $0 \%$ & UF & $19 \pm 1$ & 98.7 & $138 \pm 69$ & 7.8 & 0.52 \\
\hline CNC1.9 XG0.1 & $1.9 \%$ & $0.1 \%$ & UF & $18 \pm 2$ & 98.8 & $361 \pm 171$ & 28.9 & 0.40 \\
\hline CNC1.6 XG0.4 & $1.6 \%$ & $0.4 \%$ & UF & $17 \pm 1$ & 98.8 & $610 \pm 246$ & 53.3 & 0.36 \\
\hline CNC2 XG0 & $2 \%$ & $0 \%$ & NF & $23 \pm 1$ & 98.5 & $10 \pm 1$ & - & 0.15 \\
\hline CNC1.9 XG0.1 & $1.9 \%$ & $0.1 \%$ & NF & $23 \pm 1$ & 98.5 & $136 \pm 12$ & 19.67 & 0.10 \\
\hline CNC1.6 XG0.4 & $1.6 \%$ & $0.4 \%$ & NF & $23 \pm 1$ & 98.5 & $237 \pm 91$ & 9.83 & 0.18 \\
\hline
\end{tabular}


The morphologies of the aerogels were investigated by scanning electron microscopy

274 (SEM). Aerogels prepared by NF showed random, or disordered, structures and no significant 275 morphological difference could be evidenced between the different compositions (Fig. SI1).

276 Indeed, when solutions were frozen in the absence of a controlled temperature gradient, the crystals

277 tend to grow with no preferred direction, resulting in isotropic pore structures (Köhnke et al., 278 2012). Figure 2 shows representative SEM images of the aerogels prepared by UF at increasing $279 \mathrm{CNC} / \mathrm{XG}$ concentration ratios (i.e. $\mathrm{CNC} 2 \mathrm{XG} 0, \mathrm{CNC1.9} \mathrm{XG0.1}$ and $\mathrm{CNC} 1.6 \mathrm{XG0.4}$ ). 280 Perpendicular and parallel sections (Fig. 2) of the cylindrical monolith show oriented structures of 281 the aerogels along the temperature gradient direction. UF-generated CNC aerogels exhibited a 282 lamellar pore structure (Fig. 2a), a common morphological feature found in the literature for 283 freeze-cast CNC aerogels (Chau et al., 2016; Dash et al., 2012; Kam et al., 2019; Munier et al., 284 2016). In contrast, the XG-CNC aerogels displayed alveolar elongated pores (Figs. 2b and 2c), 285 similar to a honeycomb structure (Pan et al., 2016) reminiscent of the morphology reported for 286 cellulose nanofiber (CNF) aerogels (Donius, Liu, Berglund, \& Wegst, 2014; Munier et al., 2016; 287 Pan et al., 2016). Increasing XG concentration induced an increase in pore size. Assuming that the 288 alveoli shape is almost circular, based on SEM images, the average cell dimension was estimated 289 at $46 \mu \mathrm{m}( \pm 15 \mu \mathrm{m})$ and $127 \mu \mathrm{m}( \pm 23 \mu \mathrm{m})$ for CNC1.9 XG0.1 and CNC1.6 XG0.4 aerogels, 290 respectively. In both cases, the pores have been found to be open since windows between the pores 291 are clearly visible, as commonly obtained for ice-templated materials. This was also confirmed by 292 the confocal images as discussed in the next section. The change from lamellar to alveolar 293 morphology in the presence of XG has been related to an increase in the viscosity of the CNC/XG 294 colloidal dispersion. ${ }^{40}$ Accordingly, we recently reported that simple mixing of XG and CNC leads 
295 to an increase of the viscosity of the dispersion and the formation of hydrogels (Talantikite, 296 Gourlay, Gall, \& Cathala, 2019). We have proposed that gelation is due to steric stabilization when 297 the CNC surface are crowded while cross-linking might occur at lower CNC/XG to form microgels 298 in agreement with our previous reports (Dammak et al., 2015; Villares et al., 2015). These 299 variations in the physicochemical environment may change ice nucleation as well as the growth of 300 ice crystals. The full understanding of the link between $\mathrm{CNC} / \mathrm{XG}$ mixture rheology properties and 301 ice nucleation and growth would require a dedicated and in-depth study that is beyond the scope 302 of the current work (Zhang \& Liu, 2018). This finding is reminiscent of a recent study on the 303 preparation of XG-CNC aerogels by 3D printing coupled with UF (Kam et al., 2019) showing that 304 higher relative amounts of $\mathrm{XG}$ increase the viscosity of the $\mathrm{CNC} / \mathrm{XG}$ suspensions and induce a 305 morphological evolution of the ice crystals, yielding to a transition from a lamellar aerogel 306 morphology a to tubular morphology or to a disordered morphology at the highest concentrations 307 (Buchtova \& Budtova, 2016; Kam et al., 2019). 

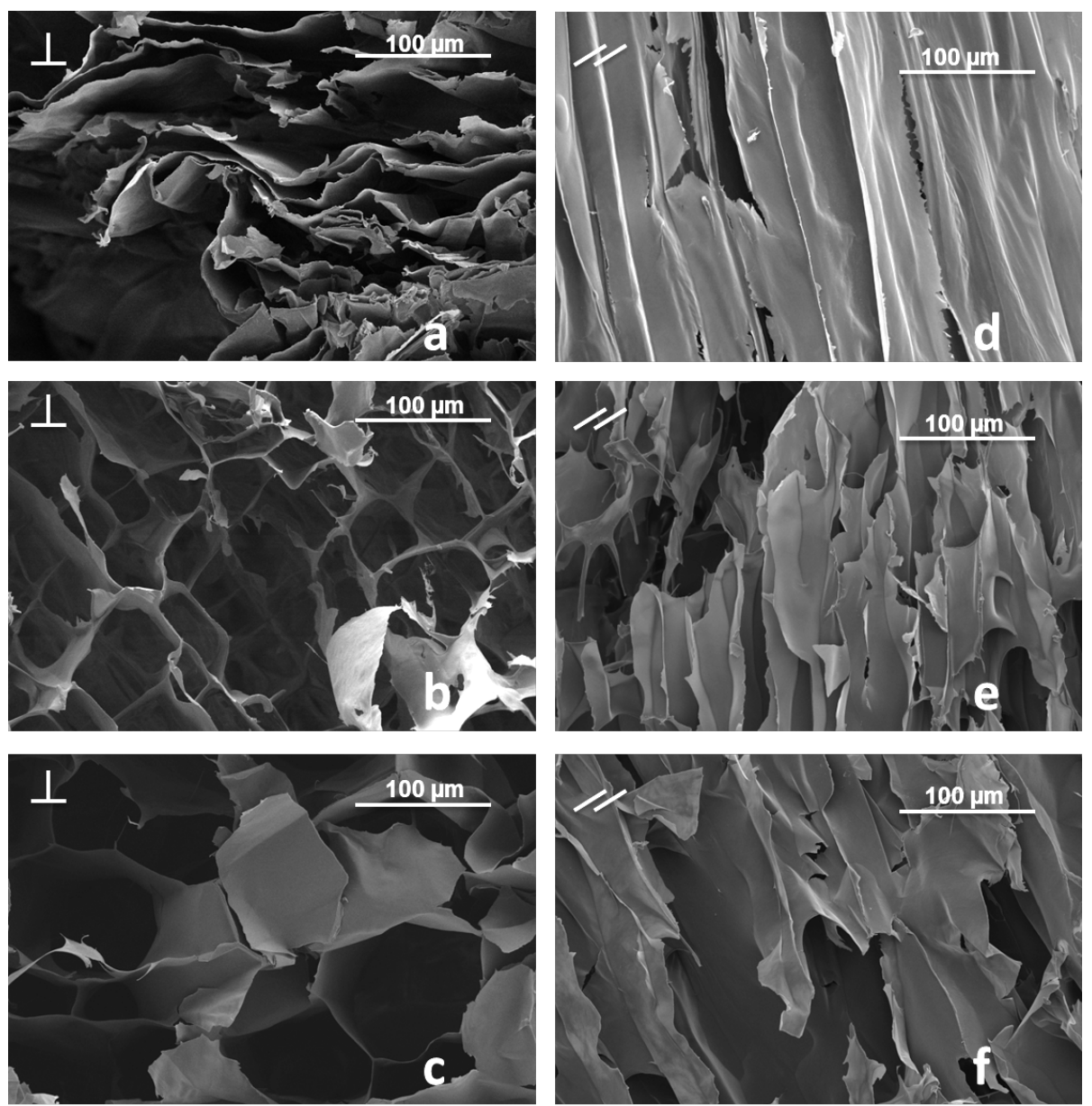

310 Figure 2: SEM micrographs of $\mathrm{CNC}$ and $\mathrm{CNC} / \mathrm{XG}$ aerogels prepared by UF. Compositions of the

311 aerogels are given as: (a, d) CNC2 XG0; (b, e) CNC1.9 XG0.1; (c, f) CNC1.6 XG0.4. Slices are

312 cut perpendicular $(\mathrm{a}, \mathrm{b}, \mathrm{c})$ and parallel $(\mathrm{d}, \mathrm{e}, \mathrm{f})$ to the freezing direction.

Aerogel morphologies were also investigated by confocal microscopy and XG was tagged

315 with rhodamine B isothyocyanate (RITC) and CNC with fluorescein isothyocyanate (FITC).

316 Typical morphologies of the aerogels prepared by UF are depicted in Figure 3. The lowest XG

317 ratio sample $(\mathrm{CNC} 1.9 \mathrm{XG} 0.1)$ yields more disordered pores than the high $\mathrm{XG}$ ratio $(\mathrm{CNC} 1.6$ 318 XG0.4) aerogels in terms of both pore section dimensions and pore alignment. In particular, the 
319 CNC1.6 XG0.4 sample displays polyhedral pore cross-sections suggesting the growth of uniform

320 ice columns during ice templating. The CNC1.9 XG0.1 sample displays a more disordered

321 structure suggesting that the ice growth phenomenon is less controlled by the thermal gradient.

322 Confocal microscopy images are in good agreement with SEM observations since larger pores are

323 observed in the case of $\mathrm{CNC} 1.6 \mathrm{XG} 0.4$ samples, in contrast with pores observed at lower $\mathrm{CNC} / \mathrm{XG}$

324 ratios. The samples were prepared from a representative zone of the monolith and connections

325 between pores can be observed in both samples. Pore connections are sometimes visible, indicating

326 that the pores are not fully closed. However, it can be stated qualitatively that the CNC1.6 XG0.4

327 sample has the most continuous wall structure of all samples observed.

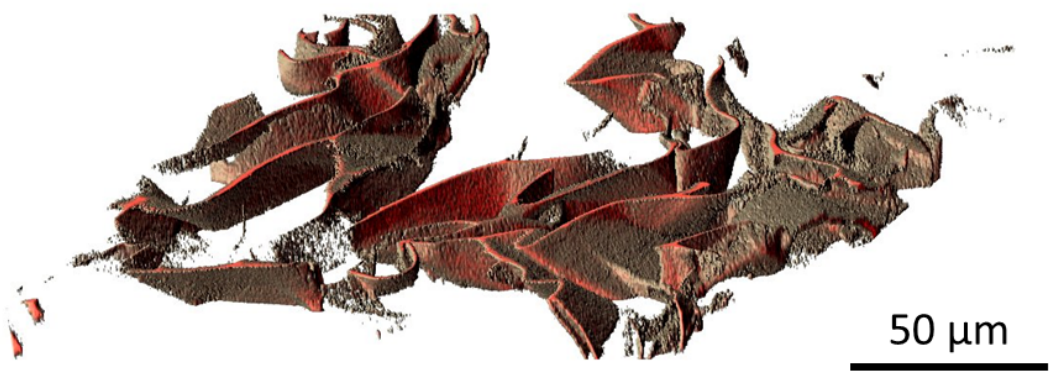

CNC1.9XG0.1

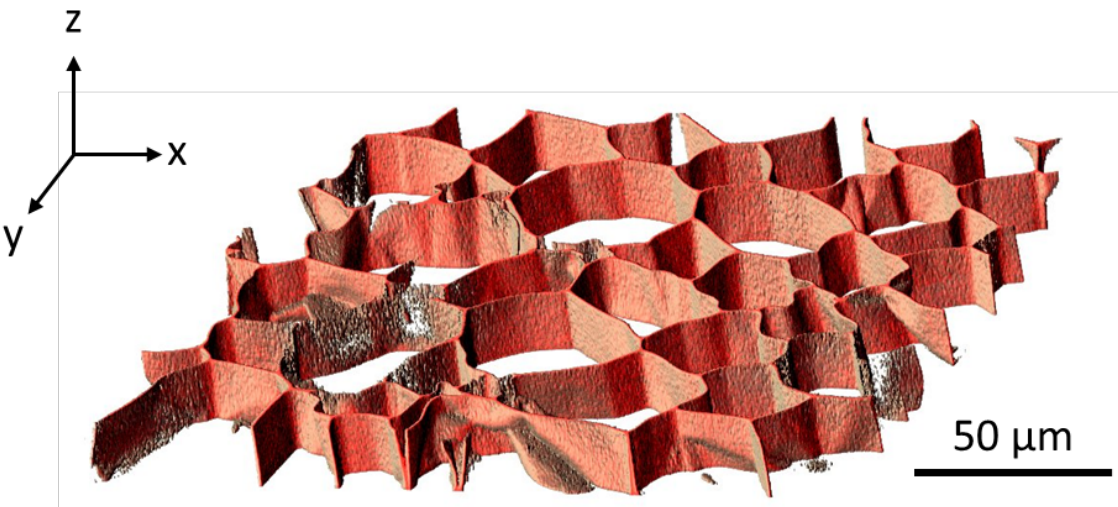

CNC1.6XG0.4 
330 Figure 3: 3D reconstruction of CNC/XG UF aerogels from confocal microscopy of the XG-RITC

331 channel (top, CNC1.9 XG0.1; bottom, CNC1.6 XG0.4). Aerogel sections were imaged after

332 lyophilization, slicing with a scalpel normal to the ice growth axis and placed in immersion oil for 333 observation. Confocal images of $180 * 180 * 15 \mu \mathrm{m}^{3}$ volume sections were acquired in $300 \mathrm{~nm} \mathrm{z}$ 334 steps. Reconstruction was conducted in FIJI software using the Volume Viewer plugin (Schindelin 335 et al., 2012).

336 The segregation of solutes from the initial solution is inherent to ice templating. Since the 337 solubility of each polysaccharide may differ during the freezing-induced segregation, it is critical 338 to assess whether both polymers are co-localized after ice-templating or if some phase separation 339 occurs, and thus to ensure that they reproduce locally the global CNC/XG ratios. Figure SI2 depicts 340 the analysis of the colocalization between the two fluorescence channels for samples CNC1.9

341 XG0.1 and CNC1.6 XG0.4. In both cases a positive correlation between the intensities of the two 342 channels, as defined by the Pearson's R value can vary from - 1 for perfect negative correlation to $343+1$ for perfect correlation. Here, the Pearson's $\mathrm{R}$ value was 0.74 and 0.84 for high- and low-XG 344 ratios, respectively indicating that $\mathrm{CNC}$ and $\mathrm{XG}$ are distributed homogeneously throughout the 345 imaged sample section and that no segregation occurs.

$347 \quad 3.3 \mathrm{CNC}$ orientation

348 X-Ray diffraction (XRD) was used to determine the azimuthal intensity profiles of the 349 (200) ring of crystalline cellulose I (Fig. SI3 and Fig. 4). When the X-ray beam is perpendicular 350 to the freezing direction, aerogels prepared by UF show diffraction patterns with a typical fiber 351 diffraction profile due to preferred orientation. This is observed as two distinct peaks at 352 approximately $90^{\circ}$ and $270^{\circ}$ in the azimuthal intensity profiles (Fig. 4a). This indicates that CNC 
353 are oriented along the freezing direction when the samples are produced by UF. When the X-ray 354 beam is parallel to the aerogel's axis, an almost flat azimuthal profile is observed (Fig. 4c). Similar 355 results were reported in previous studies for $0.5 \% \mathrm{CNF}$ and $1.5 \% \mathrm{CNC}$ aerogels prepared by 356 directional freeze-casting, showing anisotropic profiles of X-ray diffraction patterns and indicating 357 that cellulose nanoparticles are also highly oriented along the freezing gradient (Munier et al., 358 2016). These diffractograms strongly contrast with the quasi-isotropic diffractograms of non359 directional freeze-cast NF aerogels that display minimal azimuthal intensity variations (Fig. 4b 360 and d).

361 The degree of orientation of CNC can be quantified by Herman's orientation factor, $f$ (Hermans, 362 Hermans, Vermaas, \& Weidinger, 1946). $f$ is calculated and presented in Table 1 for the different 363 aerogels. The aerogels prepared by NF are characterized by very low Herman's factors compared 364 to aerogels prepared by UF (Table1), confirming that the UF aerogels bear oriented CNC within 365 their walls. It has been proposed that CNC can align through compaction during freeze-drying or 366 by the growing ice front during unidirectional freezing (Han, Zhou, Wu, Liu, \& Wu, 2013). Indeed, 367 during freezing of aqueous suspensions of CNCs, water is frozen into ice crystals and most CNC 368 above a critical size are trapped by the moving ice front and confined in interstitial spaces between 369 the ice crystals (Deville, Saiz, Nalla, \& Tomsia, 2006; Han et al., 2013). CNC aerogels prepared 370 by UF display a higher alignment than $\mathrm{XG} / \mathrm{CNC}$ aerogels. We correlate the presence of XGs in 371 these aerogels to their less-aligned microstructure. In a previous study dedicated to CNC and CNF 372 aerogels prepared by UF, it was shown that cellulose particles were oriented when the 373 concentration of the dispersion was above a critical value $(0.2 \mathrm{wt} \%$ for CNC and $0.08 \mathrm{wt} \%$ for 374 CNF) (Munier et al., 2016). CNF were slightly less oriented compared to CNC in the freeze-cast 375 aerogels, which was attributed to the rod-like shape of the rigid CNC compared to the more flexible 
376 CNF (Munier et al., 2016). Similar assumptions can be made here. Rigid CNC can easily reorient

377 due to a local concentration increase or shearing during ice growth, as opposed to a $\mathrm{CNC} / \mathrm{XG}$

378 network that likely forms a less mobile assembly, with collective motion.

379
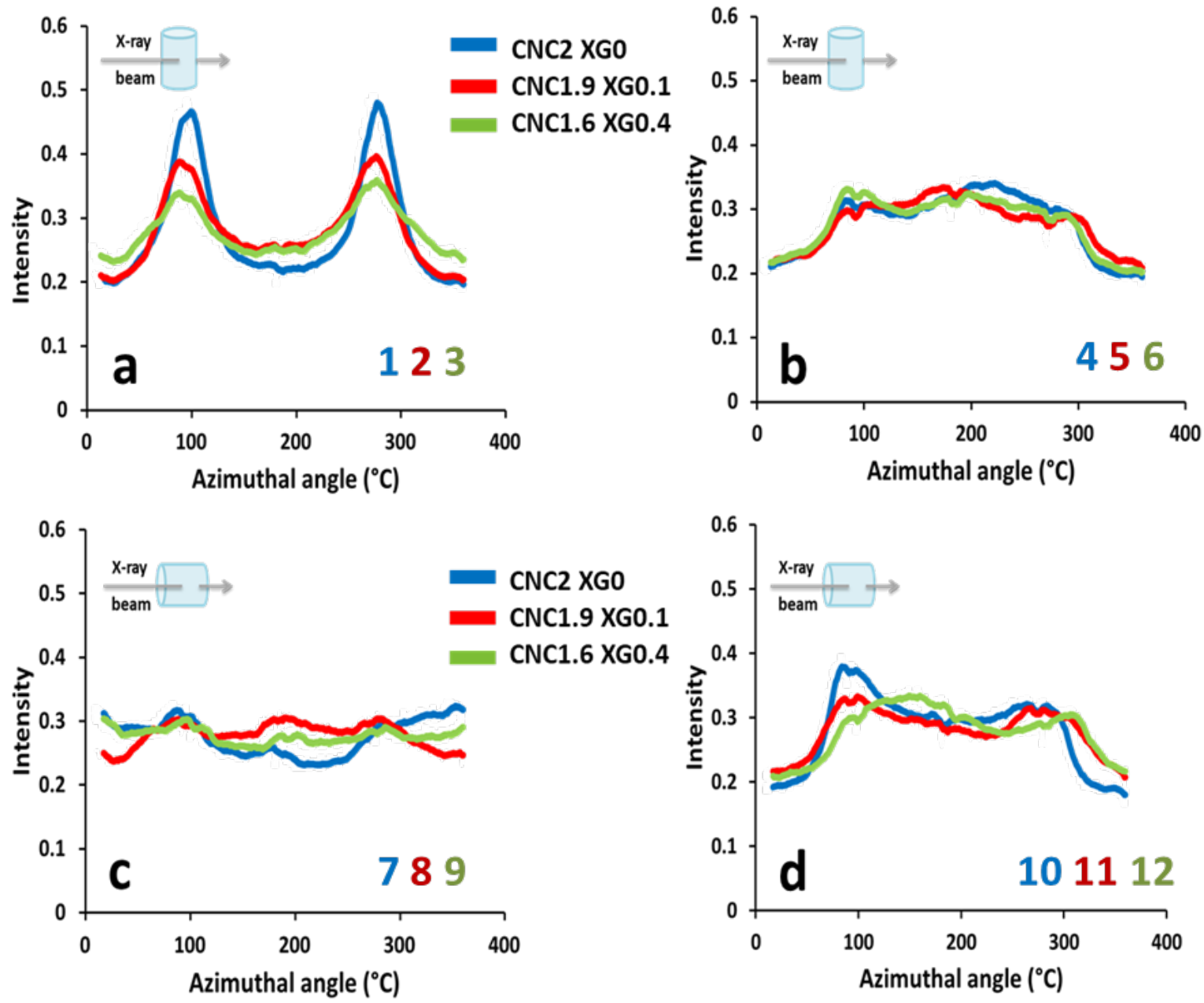

Figure 4: X-ray diffraction investigation showing azimuthal intensity profiles of the aerogels (Figure SI3) of the aerogels are given above the azimuthal intensity profiles. 


\subsection{Mechanical properties}

The mechanical properties of the aerogels were studied by uniaxial compression in the

388 longitudinal direction both on UF and NF samples. Figure 5 shows representative compression

389 curves for the aerogels prepared by UF (Figure 5a) and NF (Figure 5b). The aerogels prepared by

390 UF (Figure 5a) show typical compressive stress-strain curves where three regions can be

391 distinguished (Gibson \& Ashby, 1999). The first linear region at low strains results from the elastic

392 deformation from which the elastic modulus can be determined. A yield stress corresponding to

393 the elastic limit at the end of the linear region is determined (Table 2). The second region with a

394 gradual increase in the stress value corresponds to the cell collapse plateau. Finally, a steep

395 increase in the stress at strains larger than ca. $60 \%$ is observed in the densification region where

396 the pore cell walls merge. For aerogels prepared by NF (Figure 5b), the stress-strain curves present

397 a less defined elastic region at low strains (the determination of yield stress is not possible for

398 CNC2 XG0), after which it progressively increases until it reaches a densification region. 

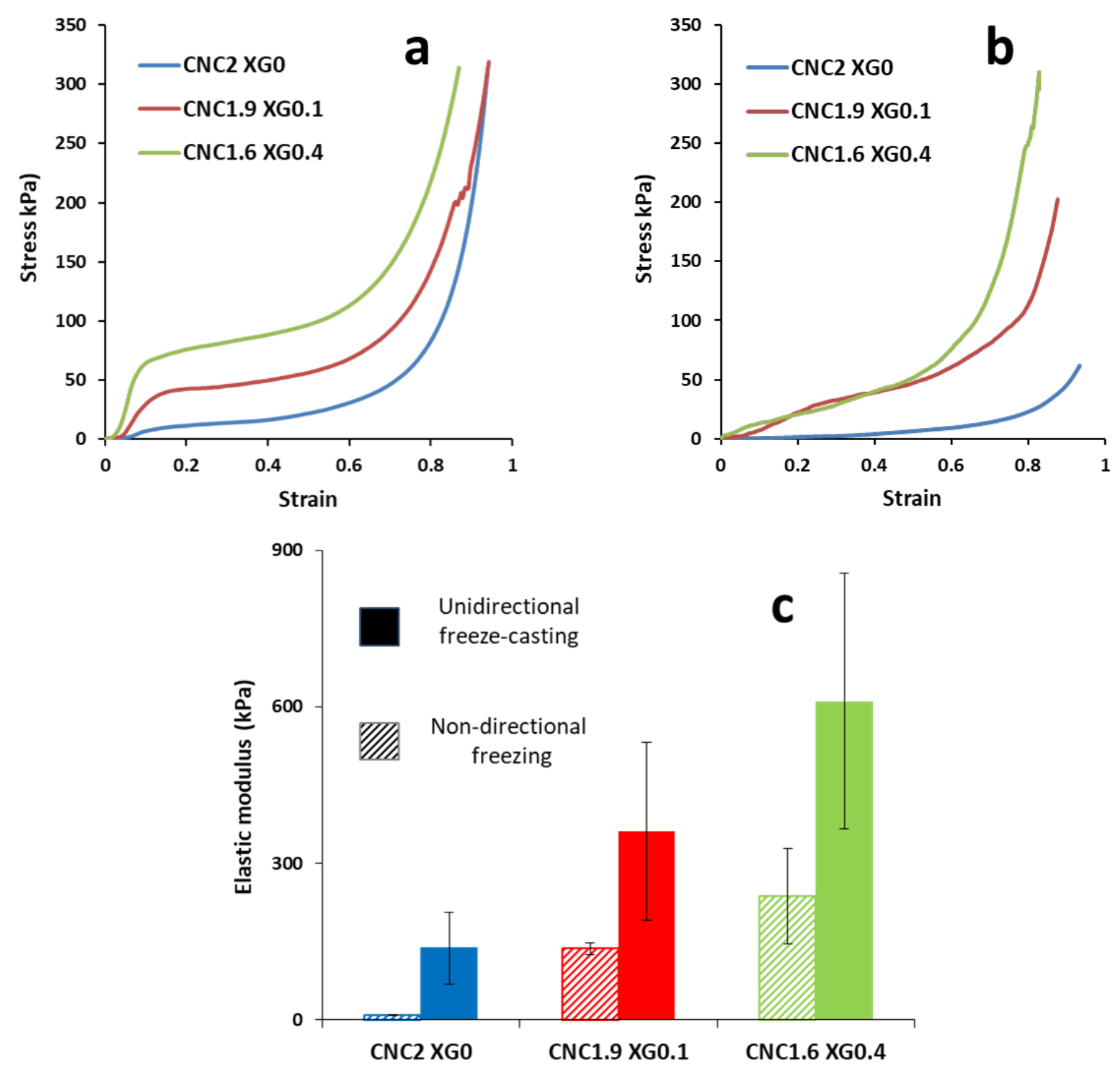

401 Figure 5: Typical stress-strain uniaxial compression curves for aerogels (CNC2 XG0; CNC1.9

402 XG0.1; CNC1.6 XG0.4) prepared by UF (a) and NF (b). A rod diagram comparing the longitudinal

403 elastic moduli $(\mathrm{kPa})$ resulting from the uniaxial compression of the aerogels (CNC2 XG0; CNC1.9

404 XG0.1; CNC1.6 XG0.4) prepared by UF and NF (c).

406 those reported in the literature and larger than for those prepared by NF(Pääkkö et al., 2008; 
Sehaqui, Salajková, Zhou, \& Berglund, 2010). In particular, CNC2 XG0 aerogels prepared by UF have a longitudinal elastic modulus 14 times higher than CNC2 XG0 prepared by NF (Table 1 \& Fig. 4). However, the influence of the freezing method is less pronounced with CNC1.9 XG0.1 and CNC1.6 XG0.4 aerogels, with only a 2.5 factor between longitudinal elastic moduli of UF and

411 NF samples. Our results clearly demonstrate that the addition of XG to CNC improved the rigidity 412 of the aerogels due to XG adsorption. This effect is magnified when pores are oriented in the 413 direction of the compression, due a high lineic relative density on UF samples compared to NF 414 samples. In fact, for aerogels prepared by UF, an elastic modulus of $610 \mathrm{kPa}$ is reached for CNC1.6 $415 \mathrm{XG} 0.4$, which is almost two times higher than CNC1.9 XG0.1 (360 kPa) and four times higher 416 than CNC2 XG0 (138 kPa). Concomitantly, the addition of XG increases the yield stress 7 times, 417 from $7.8 \mathrm{kPa}$ for $\mathrm{CNC} 2 \mathrm{XG} 0$ to $53.3 \mathrm{kPa}$ for CNC1.6 XG0.4. This result indicates that XG 418 increases the resistance to the deformation before irreversible damage. This result is noteworthy 419 since it highlights the importance of $\mathrm{XG}$ for the cell wall mechanical resistance, a resistance that 420 is often assumed to be provided by cellulose alone. As a comparison, the incorporation of XG in 421 microfibrillated cellulose (MFC) aerogels (2/8 XG/MFC), with an equivalent total dried mass 422 fraction of $2 \%$, increased their elastic modulus from $440 \mathrm{kPa}$ to $970 \mathrm{kPa}$ (Xu et al., 2013). This 423 result is in the same range as $\mathrm{CNC1} .6 \mathrm{XG0.4}$ whereas MFC have considerably higher aspect ratios 424 than CNC. It is also important to point out that the highest modulus is obtained for the sample 425 where $\mathrm{CNC}$ orientation degree is the lowest, suggesting that such this alignment is detrimental to 426 compression properties, in accordance with the current knowledge on compression wood (high 427 microfibril angle) with respect to tension wood (low microfibril angle, strong longitudinal 428 alignement). 
Aerogels prepared by UF were examined after immersion in ink-colored water (Fig. 6).

432 The cylindrical shape of pure CNC aerogels was quickly lost upon swelling (Fig. 6b). The 433 dispersion took $5 \mathrm{~h}$ for $\mathrm{CNC} 1.9 \mathrm{XG0.1}$ (Fig. 6c), whereas CNC1.6 XG0.4 retained its structural 434 cohesion for up to two weeks after immersion (Fig. 6 d, e). This experiment, despite its simplicity, 435 clearly demonstrates the efficiency of the $\mathrm{CNC} / \mathrm{XG}$ cross-links. These cross-links have a similar 436 effect on the water stability of the aerogels than covalent cross-links. For instance, a previous 437 report on xylan/CNC aerogels prepared by UF showed that xylan oxidation was necessary to create 438 covalent bonds during drying and therefore to obtain water-stable aerogels, whereas unmodified 439 xylan led to composite aerogels that were easily dispersed in water (Köhnke et al., 2014) Similar 440 results can therefore be obtained without the use of specific chemicals.

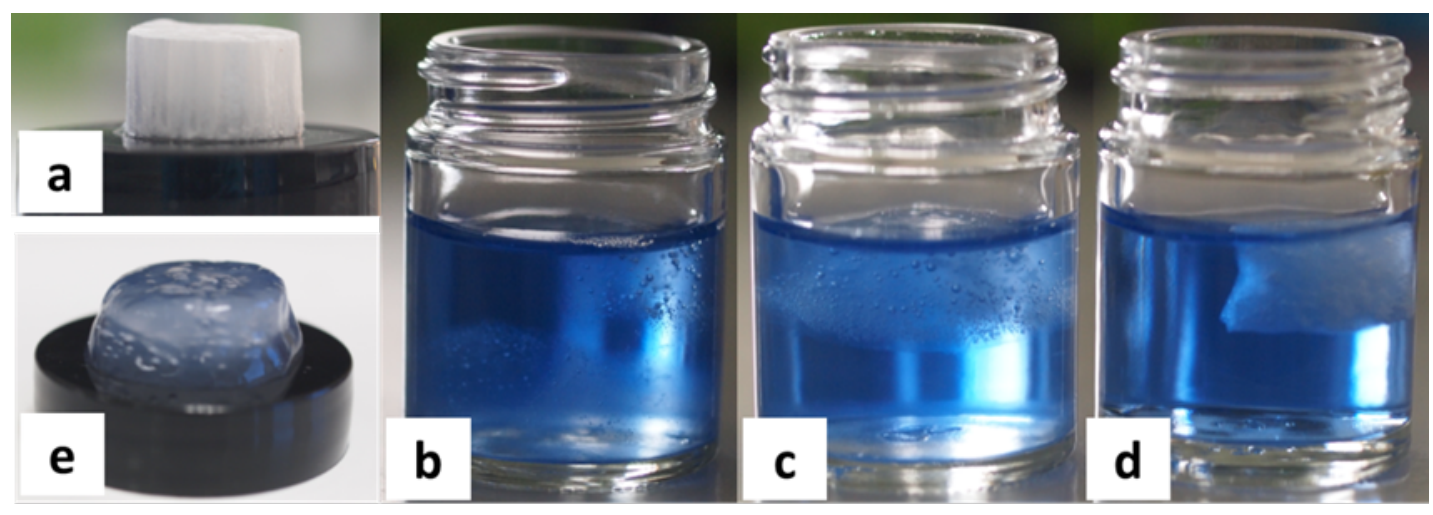

443 Figure 6: Photo illustrating an example of the freeze-cast aerogel before immersion in water (a) 444 and after 4 hours (b, c, d) and 2 weeks (e). The aerogels used in this experiment were prepared by $445 \mathrm{UF}$ and consist of CNC2 XG0 (b), CNC1.9 XG0.1 (c) and CNC1.6 XG0.4 (d, e). 


\section{DISCUSSION}

Aerogels of $\mathrm{CNC} / \mathrm{XG}$ mixtures have been successfully prepared by employing the unidirectional freeze-casting technique, where the pore morphology of the material was controlled by the freezing conditions. It has been shown that the addition of XG changed the morphology of

453 the $\mathrm{CNC}$ aerogels from lamellar to alveolar. The pore size was larger when higher XG amounts were present in the aerogel. Uniaxial compression tests showed that UF provided stronger aerogels than non-directional freezing. Non-directional freezing resulted in random unordered porous structures. This result is in agreement with previous works showing that aligning cellulose or chitin nanofibers can enhance both the stiffness and the strength of dense films (Gindl \& Keckes, 2007;

458 Kvien \& Oksman, 2007; Sehaqui et al., 2012) or filaments (Hakansson et al., 2014; Torres459 Rendon, Schacher, Ifuku, \& Walther, 2014). It has been also shown that the freeze-cast aerogels 460 with the highest relative amount of $\mathrm{XG}(\mathrm{CNC} 1.6 \mathrm{XG} 0.4)$ bore the largest pores. These pores were 461 alveolar. These samples also had the highest elastic modulus compared to the other aerogels with 462 lower amounts of XG. Hence, the distinct mechanical behaviors of the aerogels prepared by UF 463 and NF can be explained by the difference in structural morphologies of the aerogels. It has to be 464 noticed that the freezing rate, that is markedly different for UF and NF methods, may impact the 465 setting of CNC-XG interactions and therefore contribute to the difference in mechanical properties. 466 Our results are consistent with literature results related to xylan-CNC aerogels, showing that the 467 strong anisotropy of the porous structure of the UF-generated structure induced greater mechanical 468 properties than random porosity obtained by NF, and that samples possessing larger pores were 469 stronger and stiffer than samples containing smaller pores (Köhnke et al., 2012).

470 X-ray diffraction investigation showed that XG has a negative effect on $\mathrm{CNC}$ orientation in the ice 471 crystal growth direction. According to Herman's factor, $\mathrm{CNC}$ are less aligned in CNC1.6 XG0.4, 
472 while the best mechanical properties are obtained with this composition. The alignment of CNC is 473 therefore not the major factor of the improved mechanical properties of $\mathrm{XG}-\mathrm{CNC}$ aerogels 474 prepared by freeze-casting. The formation of a co-continuous network of rigid nanocrystals relying 475 on hydrogen bonding and van der Waals interactions between XG and CNC could be the reason 476 for the observed mechanical improvement, since relatively isotropic aerogels were affected that 477 way. This co-continuous network is also efficient at providing a much better resistance to water 478 immersion as illustrated by the CNC1.6 XG0.4 sample. In contrast, simply percolated CNC 479 aerogels without any $\mathrm{XG}$ addition are prone to water redispersion due to the lack of intimate 480 binding between the rigid $\mathrm{CNC}$ rods alone, probably due to steric effects.

481 It is known that the high stiffness of $\mathrm{CNC}$ reinforced composites results from the hydrogen482 bonding forces that hold the percolating network of fibers together (Buchtova \& Budtova, 2016; 483 Favier, Chanzy, \& Cavaille, 1995)'(Capadona, Shanmuganathan, Tyler, Rowan, \& Weder, 2008). 484 However, this stiffness increase comes at the price of interparticle binding in wet environments, a 485 function that the matrix provides. The influence of a co-continuous polymer network on moisture 486 resistance was also observed when cellulose was used instead of XG (Lourdin et al., 2016). 487 However the ease of use of XG constitutes a breakthrough in that this process is water-based and 488 doesn't require to use hazardous ionic liquids or chemical reagents.

489 This behavior of XG is well consistent with previous results on $\mathrm{XG}$ and bacterial nanocellulose 490 hydrogel as a cell wall analogues, where tethers of XG between the cellulose fibers have been 491 evidenced (Lopez-Sanchez et al., 2015). In addition, these XG segments were still present after 492 extensive washing of the samples, indicating that XG interacts strongly with the cellulose fibers in 493 water-saturated environments. It was also shown that XG and bacterial nanocellulose hydrogels 494 were approximately half the thickness of bacterial nanocellulose-only samples produced after the 
same fermentation time, likely due to the effect of xyloglucan crosslinks bringing the cellulose

496 fibers closer and leading to a more compact structure (Lopez-Sanchez et al., 2015).

497 In fact, the challenge of creating aerogels from CNCs relies on the ability to form effective water498 stable bonds between individual rigid particles. CNC aerogels based on hydrogen bonding and 499 physical cross-links may suffer in mechanical performance and may permanently collapse or 500 redisperse in water. Thus, in the most of the previous studies that examine CNC aerogels, CNCs 501 were used as a nanofiller within a polymer matrix to give a reinforced gel (Coulibaly et al., 2013; 502 Xu et al., 2013; Yang, Bakaic, Hoare, \& Cranston, 2013) or used alone to form a networked 503 structure by chemical or physical cross-linking (Dash et al., 2012; Fumagalli, Sanchez, Boisseau, 504 \& Heux, 2013; Heath \& Thielemans, 2010; Yang \& Cranston, 2014). In this work, CNC were 505 cross-linked with XG in water, without any chemical treatment. Moreover, freeze-cast XG-CNC 506 biomimetic aerogels were obtained and showed well-defined architecture and improved 507 mechanical properties. These results provided a better insight into the contribution of XG to the 508 mechanical properties of the plant cell wall and provided promising strategies to design new fully 509 bio-based materials in green synthesis and processing conditions

\section{CONCLUSIONS}

512 Novel bioinspired $\mathrm{CNC} / \mathrm{XG}$ aerogels processed by the UF were successfully prepared 513 without chemical modification of the biopolymers. The addition of XG changed the morphology

514 of $\mathrm{CNC}$ aerogels from lamellar to alveolar, resulting in a honeycomb-like microstructure, and 515 increased both the elastic modulus and the aqueous stability of the aerogels. This can be explained 516 by the interactions between $\mathrm{XG}$ chains and $\mathrm{CNC}$ rigid nanocrystals, that not only increased the 517 viscosity of the starting mixture but also allowed the formation of strongly interacting $\mathrm{CNC} / \mathrm{XG}$ 
network. Therefore, the $\mathrm{CNC} / \mathrm{XG}$ ratio has a profound impact of the properties of the aerogels.

519 Increasing the $\mathrm{CNC} / \mathrm{XG}$ ratio enhances the mechanical properties of the aerogels but decreases the

520 orientation of $\mathrm{CNCs}$ within their walls. It is likely that the high relative $\mathrm{XG}$ amounts increased the

521 interactions between the $\mathrm{CNC}$, thus limiting their mobility and ability to orient during UF. Such a

522 strengthening of inter-CNC interactions would also explain the enhanced stability of aerogels in

523 water. Importantly, these interactions are mediated by the XG molecules and therefore depend on

524 their conformation on the CNC surface. Based on the different concentration regimes studied here,

525 a loop and tail XG conformation seems more favorable than a train conformation. Altogether the

526 influence of $\mathrm{XG}$ on the functional properties of the aerogels is multifaceted and needs to be

527 considered at different scales. These results therefore highlight the possibility to design

528 mechanically-robust and water-stable bioaerogels with well-defined architectures without

529 chemical treatment but relying only the optimal setting of intermolecular forces.

\section{$530 \quad$ Funding Sources}

531 This work is a contribution to the Labex Serenade program (no. ANR-11-LABX-0064) funded by 532 the "Investissements d'Avenir" programme of the French National Research Agency (ANR) 533 through the A*MIDEX project (no. ANR-11-IDEX-0001-02).

\section{ASSOCIATED CONTENT}

\section{AUTHOR INFORMATION}

\section{Corresponding Author}

537 *E-mail: bernard.cathala@inrae.fr

$538 \quad$ Present address

539 INRAE, UR BIA, F-44316, Nantes, France 
Buchtova, N., \& Budtova, T. (2016). Cellulose aero-, cryo- and xerogels: towards understanding of morphology control. Cellulose, 23(4), 2585-2595.

Burgert, I. (2006). Exploring the micromechanical design of plant cell walls. American journal of botany, 93(10), 1391-1401.

Capadona, J. R., Shanmuganathan, K., Tyler, D. J., Rowan, S. J., \& Weder, C. (2008). StimuliResponsive Polymer Nanocomposites Inspired by the Sea Cucumber Dermis. Science, 319(5868), 1370-1374.

Chau, M., De France, K. J., Kopera, B., Machado, V. R., Rosenfeldt, S., Reyes, L., Chan, K. J., Förster, S., Cranston, E. D., \& Hoare, T. (2016). Composite hydrogels with tunable anisotropic morphologies and mechanical properties. Chemistry of Materials, 28(10), 3406-3415.

Chu, G., Qu, D., Zussman, E., \& Xu, Y. (2017). Ice-assisted assembly of liquid crystalline cellulose nanocrystals for preparing anisotropic aerogels with ordered structures. Chemistry of Materials, 29(9), 3980-3988.

Cosgrove, D. J. (2005). Growth of the plant cell wall. Nature reviews molecular cell biology, 6(11), 850.

Cosgrove, D. J. (2014). Re-constructing our models of cellulose and primary cell wall assembly. Current opinion in plant biology, 22, 122-131.

Coulibaly, S., Roulin, A., Balog, S., Biyani, M. V., Foster, E. J., Rowan, S. J., Fiore, G. L., \& Weder, C. (2013). Reinforcement of optically healable supramolecular polymers with cellulose nanocrystals. Macromolecules, 47(1), 152-160.

Dammak, A., Quémener, B., Bonnin, E., Alvarado, C., Bouchet, B., Villares, A., Moreau, C. 1., \& Cathala, B. (2015). Exploring architecture of xyloglucan cellulose nanocrystal complexes through enzyme susceptibility at different adsorption regimes. Biomacromolecules, 16(2), 589-596.

Dash, R., Li, Y., \& Ragauskas, A. J. (2012). Cellulose nanowhisker foams by freeze casting. Carbohydrate polymers, 88(2), 789-792.

de Belder, A., \& Granath, K. (1973). Preparation and Properties of Fluorescein-Labelled Dextrans. Carbohydrate Research, 30, 375-378.

De France, K. J., Hoare, T., \& Cranston, E. D. (2017). Review of Hydrogels and Aerogels Containing Nanocellulose. Chemistry of Materials, 29(11), 4609-4631.

Deville, S. (2008). Freeze-casting of porous ceramics: a review of current achievements and issues. Advanced Engineering Materials, 10(3), 155-169.

Deville, S. (2010). Freeze-casting of porous biomaterials: structure, properties and opportunities. Materials, 3(3), 1913-1927.

Deville, S., Saiz, E., Nalla, R. K., \& Tomsia, A. P. (2006). Freezing as a path to build complex composites. Science, 311(5760), 515-518.

Deville, S., Saiz, E., \& Tomsia, A. P. (2006). Freeze casting of hydroxyapatite scaffolds for bone tissue engineering. Biomaterials, 27(32), 5480-5489.

Donius, A. E., Liu, A., Berglund, L. A., \& Wegst, U. G. (2014). Superior mechanical performance of highly porous, anisotropic nanocellulose-montmorillonite aerogels prepared by freeze casting. Journal of the mechanical behavior of biomedical materials, 37, 88-99.

Favier, V., Chanzy, H., \& Cavaille, J. (1995). Polymer nanocomposites reinforced by cellulose whiskers. Macromolecules, 28(18), 6365-6367. 
Fricke, J., \& Tillotson, T. (1997). Aerogels: production, characterization, and applications. Thin solid films, 297(1-2), 212-223.

Fumagalli, M., Sanchez, F., Boisseau, S. M., \& Heux, L. (2013). Gas-phase esterification of cellulose nanocrystal aerogels for colloidal dispersion in apolar solvents. Soft Matter, 9(47), 11309-11317.

Ghorbani, F., Nojehdehian, H., \& Zamanian, A. (2016). Physicochemical and mechanical properties of freeze cast hydroxyapatite-gelatin scaffolds with dexamethasone loaded PLGA microspheres for hard tissue engineering applications. Materials Science and Engineering: C, 69, 208-220.

Gibson, L. J., \& Ashby, M. F. (1999). Cellular solids: structure and properties: Cambridge university press.

Gindl, W., \& Keckes, J. (2007). Drawing of self-reinforced cellulose films. Journal of Applied Polymer Science, 103(4), 2703-2708.

Hakansson, K. M. O., Fall, A. B., Lundell, F., Yu, S., Krywka, C., Roth, S. V., Santoro, G., Kvick, M., Wittberg, L. P., Wagberg, L., \& Soderberg, L. D. (2014). Hydrodynamic alignment and assembly of nanofibrils resulting in strong cellulose filaments. Nature Communications, 5.

Han, J., Zhou, C., Wu, Y., Liu, F., \& Wu, Q. (2013). Self-assembling behavior of cellulose nanoparticles during freeze-drying: effect of suspension concentration, particle size, crystal structure, and surface charge. Biomacromolecules, 14(5), 1529-1540.

Heath, L., \& Thielemans, W. (2010). Cellulose nanowhisker aerogels. Green Chemistry, 12(8), 1448-1453.

Hermans, J., Hermans, P., Vermaas, D., \& Weidinger, A. (1946). Quantitative evaluation of orientation in cellulose fibres from the X-ray fibre diagram. Recueil des Travaux Chimiques des Pays-Bas, 65(6), 427-447.

Jiménez-Saelices, C., Seantier, B., Grohens, Y., \& Capron, I. (2018). Thermal Superinsulating Materials Made from Nanofibrillated Cellulose-Stabilized Pickering Emulsions. ACS applied materials \& interfaces, 10(18), 16193-16202.

Kam, D., Chasnitsky, M., Nowogrodski, C., Braslavsky, I., Abitbol, T., Magdassi, S., \& Shoseyov, O. (2019). Direct Cryo Writing of Aerogels via 3D Printing of Aligned Cellulose Nanocrystals Inspired by the Plant Cell Wall. Colloids and Interfaces, 3(2), 46.

Karaaslan, M. A., Tshabalala, M. A., Yelle, D. J., \& Buschle-Diller, G. (2011). Nanoreinforced biocompatible hydrogels from wood hemicelluloses and cellulose whiskers. Carbohydrate polymers, 86(1), 192-201.

Kim, K. H., Oh, Y., \& Islam, M. F. (2012). Graphene coating makes carbon nanotube aerogels superelastic and resistant to fatigue. Nature Nanotechnology, 7(9), 562-566.

Klemm, D., Kramer, F., Moritz, S., Lindström, T., Ankerfors, M., Gray, D., \& Dorris, A. (2011). Nanocelluloses: a new family of nature-based materials. Angewandte Chemie International Edition, 50(24), 5438-5466.

Köhnke, T., Elder, T., Theliander, H., \& Ragauskas, A. J. (2014). Ice templated and cross-linked xylan/nanocrystalline cellulose hydrogels. Carbohydrate polymers, 100, 24-30.

Köhnke, T., Lin, A., Elder, T., Theliander, H., \& Ragauskas, A. J. (2012). Nanoreinforced xylancellulose composite foams by freeze-casting. Green Chemistry, 14(7), 1864-1869.

Kvien, I., \& Oksman, K. (2007). Orientation of cellulose nanowhiskers in polyvinyl alcohol. Applied Physics a-Materials Science \& Processing, 87(4), 641-643.

Lakes, R. (1993). Materials with structural hierarchy. Nature, 361(6412), 511. 
Lee, J., \& Deng, Y. (2011). The morphology and mechanical properties of layer structured cellulose microfibril foams from ice-templating methods. Soft Matter, 7(13), 6034-6040.

Lopez-Sanchez, P., Cersosimo, J., Wang, D., Flanagan, B., Stokes, J. R., \& Gidley, M. J. (2015). Poroelastic mechanical effects of hemicelluloses on cellulosic hydrogels under compression. Plos one, 10(3), e0122132.

Lourdin, D., Peixinho, J., Breard, J., Cathala, B., Leroy, E., \& Duchemin, B. (2016). Concentration driven cocrystallisation and percolation in all-cellulose nanocomposites. Cellulose, 23(1), 529-543.

Munier, P., Gordeyeva, K., Bergström, L., \& Fall, A. B. (2016). Directional freezing of nanocellulose dispersions aligns the rod-like particles and produces low-density and robust particle networks. Biomacromolecules, 17(5), 1875-1881.

Pääkkö, M., Vapaavuori, J., Silvennoinen, R., Kosonen, H., Ankerfors, M., Lindström, T., Berglund, L. A., \& Ikkala, O. (2008). Long and entangled native cellulose I nanofibers allow flexible aerogels and hierarchically porous templates for functionalities. Soft Matter, 4(12), 2492-2499.

Pan, Z.-Z., Nishihara, H., Iwamura, S., Sekiguchi, T., Sato, A., Isogai, A., Kang, F., Kyotani, T., \& Yang, Q.-H. (2016). Cellulose nanofiber as a distinct structure-directing agent for xylem-like microhoneycomb monoliths by unidirectional freeze-drying. ACS nano, 10(12), 10689-10697.

Saxena, A., Elder, T. J., Pan, S., \& Ragauskas, A. J. (2009). Novel nanocellulosic xylan composite film. Composites Part B: Engineering, 40(8), 727-730.

Scheller, H. V., \& Ulvskov, P. (2010). Hemicelluloses. Annual review of plant biology, 61.

Schindelin, J., Arganda-Carreras, I., Frise, E., Kaynig, V., Longair, M., Pietzsch, T., Preibisch, S., Rueden, C., Saalfeld, S., Schmid, B., Tinevez, J. Y., White, D. J., Hartenstein, V., Eliceiri, K., Tomancak, P., \& Cardona, A. (2012). Fiji: an open-source platform for biologicalimage analysis. Nature Methods, 9(7), 676-682.

Sehaqui, H., Mushi, N. E., Morimune, S., Salajkova, M., Nishino, T., \& Berglund, L. A. (2012). Cellulose Nanofiber Orientation in Nanopaper and Nanocomposites by Cold Drawing. ACS applied materials \& interfaces, 4(2), 1043-1049.

Sehaqui, H., Salajková, M., Zhou, Q., \& Berglund, L. A. (2010). Mechanical performance tailoring of tough ultra-high porosity foams prepared from cellulose I nanofiber suspensions. Soft Matter, 6(8), 1824-1832.

Svagan, A. J., Jensen, P., Dvinskikh, S. V., Furó, I., \& Berglund, L. A. (2010). Towards tailored hierarchical structures in cellulose nanocomposite biofoams prepared by freezing/freezedrying. Journal of Materials Chemistry, 20(32), 6646-6654.

Szepes, A., Ulrich, J., Farkas, Z., Kovács, J., \& Szabó-Révész, P. (2007). Freeze-casting technique in the development of solid drug delivery systems. Chemical Engineering and Processing: Process Intensification, 46(3), 230-238.

Talantikite, M., Gourlay, A., Gall, S.-L., \& Cathala, B. (2019). Influence of Xyloglucan Molar Mass on Rheological Properties of Cellulose Nanocrystal/Xyloglucan Hydrogels. Journal of Renewable Materials, 7(12), 1381--1390.

Torres-Rendon, J. G., Schacher, F. H., Ifuku, S., \& Walther, A. (2014). Mechanical Performance of Macrofibers of Cellulose and Chitin Nanofibrils Aligned by Wet-Stretching: A Critical Comparison. Biomacromolecules, 15(7), 2709-2717.

Villares, A., Moreau, C., Dammak, A., Capron, I., \& Cathala, B. (2015). Kinetic aspects of the adsorption of xyloglucan onto cellulose nanocrystals. Soft Matter, 11(32), 6472-6481. 
679 Wicklein, B., Kocjan, A., Salazar-Alvarez, G., Carosio, F., Camino, G., Antonietti, M., \& 680 Bergström, L. (2015). Thermally insulating and fire-retardant lightweight anisotropic foams based on nanocellulose and graphene oxide. Nature Nanotechnology, 10(3), 277. nanocrystals vs. cellulose nanofibrils: a comparative study on their microstructures and effects as polymer reinforcing agents. ACS applied materials \& interfaces, 5(8), 29993009.

Yang, X., Bakaic, E., Hoare, T., \& Cranston, E. D. (2013). Injectable polysaccharide hydrogels reinforced with cellulose nanocrystals: morphology, rheology, degradation, and cytotoxicity. Biomacromolecules, 14(12), 4447-4455.

Yang, X., \& Cranston, E. D. (2014). Chemically cross-linked cellulose nanocrystal aerogels with shape recovery and superabsorbent properties. Chemistry of Materials, 26(20), 6016-6025. Yin, K., Divakar, P., \& Wegst, U. G. (2019). Freeze-casting porous chitosan ureteral stents for improved drainage. Acta biomaterialia, 84, 231-241.

Zhang, Z., \& Liu, X.-Y. (2018). Control of ice nucleation: freezing and antifreeze strategies. Chemical Society Reviews, 47(18), 7116-7139. 